\title{
К 3О-ЛЕТИЮ ВЫПОЛНЕНИЯ ПЕРВОЙ ЛАПАРОСКОПИЧЕСКОЙ ХОЛЕЦИСТЭКТОМИИ В РОССИИ: НАЧАЛО СТАНОВЛЕНИЯ ЭВОЛЮЦИОННОЙ ТЕХНОЛОГИИ
}

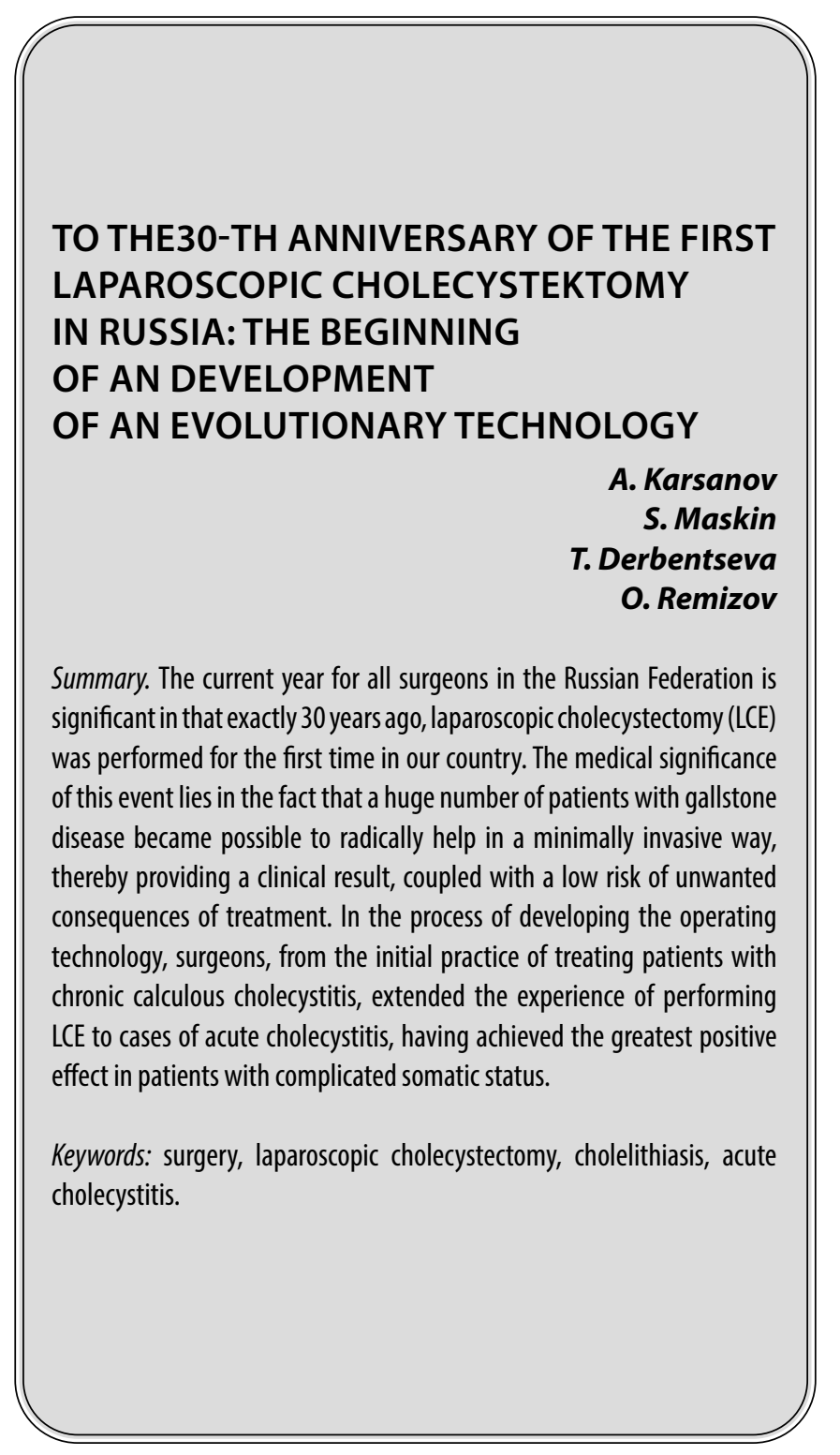

B начале 2021 года исполняется 30 лет с того исторического момента, когда в Российской Федерации была впервые успешно выполнена лапароскопическая холецистэктомия (ЛХЭ) по поводу хронического калькулезного холецистита. Отдавая дань уважения первопроходцам метода Ю.И. Галлингеру, А.Д.Тимошину, А.С. Балалыкину и их соратникам, считаем своим долгом отразить в данной статье ту профессиональную ситуацию с лечением пациентов осложненной желчно-
Карсанов Алан Мухарбекович

К.м.н., дочент, ФГБОУ ВО «Северо-Осетинская государственная медицинская академия» (2. Владикавказ) karsan@inbox.ru

Маскин Сергей Сергеевич

Д.м.н., профессор, ФГБОУ ВО «Волгоградский государственный медицинский университет»

(2. Волгоград)

maskins@bk.ru

Дербенцева Татьяна Викторовна

К.м.Н., ассистент, ФГБОУ ВО «Волгоградский государственный медицинский университет»

(г. Волгоград)

TVDerbentseva@volgmed.ru

Ремизов Олег Валерьевич

Д.м.н., ректор, ФГБОУ ВО «Северо-Осетинская государственная медицинская академия»

(2. Владикавказ)

oleg_remizov@mail.ru

Аннотация. Текущий год для всех хирургов Российской Федерации знаменателен тем, что ровно 30 лет назад в нашей стране была впервые выполнена лапароспическая холецистәктомия (ЛХЭ). Медицинское значение этого события заключается в том, что огромному числу пациентов с желчнокаменной болезнью стало возможным радикально помочь минимально инвазивным способом, обеспечив, тем самым, клинический результат вкупе с низким риском нежелательных последствий лечения. В процессе разработки технологии оперирования хирурги, от первоначальной практики лечения пациентов с хроническим калькулезным холециститом, распространили опыт выполнения ЛХЭ на случаи острого холецистита, добившись наибольшего положительного эффекта у пациентов с осложненным соматическим статусом.

Ключевые слова: хирургия, лапароскопическая холецистэктомия, желчнокаменная болезнь, острый холецистит.

каменной болезнью (ЖКБ), которая сложилась в мире и в нашей стране на тот исторический момент.

К моменту открытия и внедрения лапароскопического способа лечения ЖКБ в мировой хирургии сложилась вполне конкретная, близкая к стагнации и практически тупиковая ситуация. Но начать следует с того, что на протяжении всей истории медицины проблема лечения ЖКБ, а особенно ее осложнений, была и остается 
одной из актуальных задач современной хирургии. ЖКБ тогда и сейчас является одним из самых распространенных заболеваний. По частоте распространенности в общемировой популяции ЖКБ может уступить, разве что только атеросклерозу [1]. ЖКБ страдает около 10\% населения мира, помимо этого за каждое десятилетие процент заболеваемости удваивается [2].

В странах Европы и США заболеваемость ЖКБ колебалась от 7 до $20 \%$ от всего населения. Среди лиц старше 40 лет она достигала 40\%, а это каждая пятая женщина и каждый десятый мужчина [3]. 22 миллиона американцев имеют конкременты в желчном пузыре, по поводу чего ежегодно в США производилось 600-700 тысяч холецистэктомий, с летальностью 0,17-1,7\% [4]. В тот период в мире ежегодно производилось более 2,5 млн. операций на желчевыводящих путях [4]. В настоящее время, по данным Всемирного союза хирургов в мире выполняется более 1,5 млн. холецистэктомий. В нашей стране больные с литогенной патологией желчных путей прочно занимали одно из первых мест в хирургических стационарах $[2,5]$. Достаточно сказать, что в России ежегодно оперировались до 120 тыс. пациентов с разными формами холецистита. В наше время, число ежегодно выполняемых холецистэктомий превышает 150 тысяч [5].

После внедрения в практику новейшего высокотехнологического эндоскопического оборудования в середине 80-х годов наступила новая эра хирургии ЖКБ родилась ЛХЭ. Выполненная в сентябре 1985 года немецким хирургом E. Muhe первая холецистэктомия через лапароскоп и его сообщение в апреле 1986 г. озаглавленное «Die erste cholecystektomie durch das laparoscop» остались незамеченными хирургами. Это была первая публикация, где использован термин «лапароскопическая холецистэктомия» хотя автор применил технику, отличающуюся от используемой в настоящее время [6].

В июне 1987 г. в Лионе Ph. Mouret и в 1988 году F. Dubois [7] выполнили ЛХЭ в современном варианте, что дало основание назвать это событие «очередной французской революцией». ЛХЭ распространяется в Европе усилиями Perissat, Mouiel, Cuschieri, Becker, Buess, Trede, Troide и др.

После первой операции, проведенной в США J. B. McKernan et W. Saye [8], в октябре 1988 года первую лазерную ЛХЭ выполнили E. Reddick и D. Olsen, они же разработали методику интраоперационной холангиографии [9]. Это считается стартом бурного развития лапароскопической методики в общей хирургии.

Первая ЛХЭ в нашей стране произведена Ю.И. Галлингером и А.Д. Тимошиным 11 января 1991 года в ВНЦХ [10], и доложена на научной конференции в Курске
(1991). Там же сообщил о успешной лХЭ по поводу хронического холецистита А.С. Балалыкин.

Ни одна операция за всю историю хирургии не имела столь бурного развития. К началу 90-х годов ЛХЭ заняла ведущее место в лечении ЖКБ в мире. Предложены и применяются 2 основные технические методики выполнения ЛХЭ: «французская» и «американская». Первая попытка сравнения двух техник была отражена в работе J. Perissat, 1993 [11], который отмечает лучшую экспозицию треугольника Calot при использовании «французской».

Хотя техника ЛХЭ, выполняемая в плановом порядке, была хорошо разработана, среди хирургов сохранялись ряд разночтений. Так J.J. Jakimowicz (1994) указывает, что важнейшими условиями безопасного удаления ЖП являются оптимальная экспозиция, осторожная препаровка, адекватная визуализация и ограниченное использование электрокоагуляции. Вместе с тем подавляющее большинство хирургов используют монополярную коагуляцию, как основной способ диссекции и гемостаза.

Различия в методиках касаются положения больного на операционном столе, расположения операционной бригады и точек доступа. Сторонники «французского» и «американского» считали оба способа эффективными, и выбор должен определяться школой и навыком хирурга. Исследовав особенности подготовки, характер осложнений, пути их предотвращения и коррекции при ЛХЭ, большинство ученых уже на раннем этапе внедрения новой технологии заключают, что 90\% всех холецистэктомий выполнимы при помощи современной лапароскопической техники. По данным В.Д. Федорова и др., (1994) ЛХЭудалось выполнить у 99\% больных хроническим холециститом.

С сожалением следует признать, растущее число и расширяющийся диапазон оперативных вмешательств не сопровождались ожидаемым снижением числа неудовлетворительных результатов и летальности [12-14]. В первую очередь это относилось к результатам лечения больных с осложненной ЖКБ, к пациентам старших возрастных групп, имеющих тяжелую сопутствующую патологию $[15,16]$. Даже спустя десятилетия после внедрения в общемировую практику ЛХЭ, проблемы лечения пациентов с ЖКБ остаются. Прежде всего следует сказать о 5-кратно превышающей частоте повреждения внепеченочных желчных протоков при выполнении ЛХЭ по сравнению с открытой операцией $[5,13,14,17]$.

Острый холецистит (OX) - одно из наиболее распространенных хирургических заболеваний. Нестандартизованный по возрасту показатель заболеваемости ОХ в Российской Федерации в 2018 г., по данным главного хирурга РФ А.Ш. Ревишвили, составил 139,0 на 100 тыс. населения (162 523 случая) [18]. В настоящее время в структуре 
острых хирургических заболеваний живота ОХ по частоте уступает только острому аппендициту [5, 18], составляя $24,8 \%$ от общего числа больных, госпитализируемых по ургентным показаниям $[18,19]$. Однако особенно важно, что у больных пожилого и старческого возраста ОХ является самым частым острым хирургическим заболеванием.

Тактика лечения ОХ обсуждалась в те годы на различных форумах хирургов в периодической печати и сборниках научных трудов, что демонстрирует насущный интерес к данной проблеме, в первую очередь обусловленный неудовлетворенностью результатами лечения. Важность кардинального решения проблемы ОХ наиболее наглядно демонстрируют цифры послеоперационной летальности, которая на тот момент составляли 4,2-9\% [20], а при присоединившихся холангите, механической желтухе, а также у пациентов старших возрастных групп с сопутствующей патологией достигает 12-23\% и более [21]. Основополагающим в данном случае является тот факт, что у больных преклонного возраста значительно чаще развиваются деструктивные формы OX, сопровождающегося всеми видами осложнений и высокой летальностью [22]. Для сравнения показатели послеоперационной летальности при хроническом холецистите не превышают 0,09-0,5\% [5, 9, 13].

Широкое распространение ЛХЭ получила в связи с повсеместной неудовлетворенностью результатами лапаротомных операций. В связи с этим среди преимуществ ЛХЭ выделялись: минимальная травматичность и минимальная кровопотеря, низкий уровень послеоперационных осложнений, быстрое восстановление практического здоровья пациентов, защита больного и медперсонала от внутрибольничной инфекции и СПИДа, сокращение сроков лечения. Наряду с очевидными преимуществами ЛХЭ имеет негативные стороны: напряженный карбоксиперитонеум, плоское изображение, использование электротермокаутеризации и увеличение вероятности электро- и термотравмы.

Показания к ЛХЭ претерпели существенную трансформацию и в целом четко сформулированы: камненосительство, калькулезный холецистит, холестероз, полипоз и другие доброкачественные опухоли желчного пузыря (ЖП), ОХ в сроки до 72 часов от начала заболевания. Достаточно часто показания к операции зависят от квалификации хирурга и состояния больного.

В основном хирурги, так же как и 30 лет назад, выделяют абсолютные противопоказания к ЛХЭ: общие противопоказания к проведению лапароскопической операций, рак ЖП, плотный паравезикальный воспалительный инфильтрат, исключающий надежную визуализацию и диссекцию элементов треугольника Calot, третий триместр беременности. Отдельные авторы относят к ним также: общий перитонит, острый холецистопанкреатит, билио- дигестивные и билиобилиарные свищи, врожденные аномалии ЖП, хроническую дуоденальную непроходимость.

Относительными противопоказаниями первоначально считали: холедохолитиаз, механическую желтуху, холангит, острый панкреатит, ОХ при сроках более 72 часов от начала заболевания, синдром Мириззи, склероатрофический ЖП, цирроз печени, портальную гипертензию, коагулопатии, перенесенные операции на органах верхнего этажа брюшной полости, псевдотуморозный панкреатит, язвенную болезнь, невправимые вентральные грыжи в эпи- и мезогастрии, инфицирование передней брюшной стенки.

В.И. Греясов и соавт., не считая противопоказаниями, все же выделяли в качестве факторов риска: наличие в анамнезе механической желтухи и лихорадки, перенесенные абдоминальные операции, ожирение III-IV ст., гепатит, цирроз печени, язвенную болезнь двенадцатиперстной кишки, толщину стенки ЖП свыше 4 мм, склероатрофический желчный пузырь, аэробилию [23].

Попытки прогнозирования вероятности успешного удаления ЖП лапароскопическим способом приводили к поиску различных триггеров интраоперационных осложнений. Так, по мнению H. Gai и H. Thiele [24], противопоказаниями к ЛХЭ при ОХ являются данные УЗИ: тугое заполнение конкрементами ЖП, склероатрофический процесс стенок ЖП, увеличение толщины его стенок более 4 мм, наличие плотных спаек в подпеченочном пространстве. Использование этих критериев в 98,5\% случаев обеспечивает быстроту и легкость ЛХЭ при ОХ.

Напротив M. Shietroma и соавт. (1997) считали лапароскопию при ОХ - главным образом диагностической процедурой, призванной выбрать оптимальный метод радикального лечения, т.е. своевременно предпочесть открытую холецистэктомию, позволяющую избежать интраоперационных повреждений билиарного тракта. Схожего мнения придерживаются А.Е. Борисов и соавт. (1998), применяя лапароскопию в качестве первого декомпрессивного этапа в лечении ОХ.

R.J. Fitzgibbons и др. 1996 [25] на большом материале пришли к выводу, что корреляция патоморфологического диагноза ОХ с интраоперационной картиной при ЛХЭ значительно более низкая, чем с данными предоперационного обследования, что не мешает успешно выполнять ЛХЭ.

Таким образом, с момента внедрения технологии ЛХЭ и по наши дни хирурги не оставляют попыток повысить эффективность, качество и безопасность хирургического лечений пациентов с осложненной ЖКБ. В ходе эволюции метода и накопления опыта хирургами противопоказания из разряда абсолютных переходили в от- 
носительные и, более того, вообще перестали считаться таковыми. Это в первую очередь относится к лечению пациентов с ОХ. Со временем алгоритм применения ЛХЭ при осложненной ЖКБ был расширен. В настоящее время многие авторы рекомендуют начинать лапароскопически любую операцию на желчных путях.
Другими ключевыми направлениями научного поиска является стандартизация методики ЛХЭ для более эффективного преодоления кривой обучения начинающих хирургов и создание условий безопасного оперирования, минимизирующих риск повреждения желчных протоков.

\section{ЛИТЕРАТУРА}

1. Эндокринология. Национальное руководство. Под ред. И. И. Дедова, Г. А. Мельниченко. ГЭОТАР-Медиа, М., 2008. — 587 с.

2. Бурцева М. А., Яшнов А. А., Коновалова О. Г., Ханина Ю. С. Современная наука: актуальные проблемы теории и практики. Серия: естественные и техничеСкие науки.-2020.- № 8.- С. 147-151.

3. Farthing M., Roberts S. E., Samuel D. G. et al. Survey of digestive health across Europe: Final report. Part 1: The burden of gastrointestinal diseases and the organisation and delivery of gastroenterology services across Europe // United European Gastroenterol J. — 2014. — Vol.2. № 6. — P. 539-543.

4. Shabanzadeh D. M. New determinants for gallstone disease? // Dan. Med. J.— 2018. — Vol.65. № 2.— B5438.

5. Хирургическая помощь в Российской Федерации. Информационно-аналитический сборник / Под ред. А.Ш. Ревишвили. - М.: ФГБУ “НМИЦ хирургии им. А. В. Вишневского", 2019. - 136 с.

6. Muhe E. Die erste Cholecystektomie durch das Laparoscop // Arch. Klin. Chir. — 1986.—Vol.2.369.— P. 804. https://doi.org/10.1007/BF01274615.

7. Zucker K. A., Reddick E. J., Bailey R. W. et al. Surgical Laparoscopy // Quality Medical Publishing. St. Louis., Missori, 1991. 359p.

8. Mc Kernan J. B. Laparoscopic cholecystectomy // Am. Surg. — 1991.—Vol.57. № 5.—P. 309-312.

9. Reddick E. J., Olsen D. O. Laparoscopic cholecystectomy, a comparision with mini-lap cholecystectomy // Surg. Endosc. — 1989.—Vol.3. № 3.— P. 131-133.

10. Галлингер Ю. И., Тимошин А. Д., Мовчун А. А. и др. Лапароскопическая холецистэктомия // Хирургия. Журнал им. Н. И. Пирогова.- 1991.— № 6.C. 130-131.

11. Perissat J. Laparoscopic cholecystectomy: the European experience // Am. J. Surg. — 1993. — Vol. 165. № 4. — P. 444-449.

12. Сажин В. П., Карсанов А. М., Сажин А. В. Лапароскопическая холецистэктомия у больных с ожирением // Эндоскоп. хирургия.— 1999.—№ 2.—C. 54-55.

13. Сажин В. П., Сажин И. В., Подъяблонская И. А., Карлов Д. И., Нуждихин А. В., Айвазян С. А. Этиология "сложных" лапароскопических холецистэктомий // Хирургия. Журнал им. Н. И. Пирогова.— 2016.- № 1.- С. 61-66.

14. Федоров И. В., Чугунов А. Н., Славин Л. Е., Славин Д. А., Федоров В. И. К 30-летию внедрения лапароскопической холецистэктомии: проблемы остаются // Казанский медицинский журнал.- 2019.—№ 3.—C. 537-66.

15. Shea J. A., Healey M. J., Berlin J. A. et al. Mortality and complications associated with laparoscopic cholecystectomy. A meta-analysis // Ann. Surg. 1996; 224: 609620. - 1996. - Vol.224. № 5. - P. 609-620.

16. Климович И. Н., Маскин С. С., Дубровин И. А., Карсанов А. М., Дербенцева Т. В. Эндовидеохирургия в диагностике и лечении послеоперационного перитонита // Вестник хирургии им. И. И. Грекова.— 2015.- № 4.— С. 113-116.

17. Емельянов С. И. Современное состояние и перспективы развития эндоскопической хирургии // Тихоокеанский медицинский журнал. - 2009.—№ 2. C. 7-10.

18. Ревишвили А. Ш., Сажин В.П., Оловянный В.Е., Захарова М. А. Современные тенденции в неотложной абдоминальной хирургии в Российской Федерации // Хирургия. Журнал им. Н. И. Пирогова. - 2020.— № 7.- С. 6-11.

19. Кульчиев А. А., Сланов А. В. Острый панкреатит. - Владикавказ: Издательско-полиграфическое предприятие им. В. Гассиева, 2008. - 134 с.

20. Климович И. Н. Пути улучшения диагностики и лечения гепаторенального синдрома у больных острой абдоминальной хирургической патологией // Автореф. дис. ... док. мед. наук. Волгоград, 2007. — 271 с.

21. Карсанов А. М., Маскин С. С., Слепушкин В.Д., Карсанова 3. О., Дербенцева Т. В., Саламова Ф. Т., Караев Т. Р. Клинико-эпидемиологическое значение системного воспаления и сепсиса // Вестник хирургии.— 2015.— № 4.— С. 99-103.

22. Жидовинов Г. Т., Климович И. Н., Матюхин В. В., Милованов А. Б. Классификация гепато-ренального синдрома у больных острой хирургической патологией // Вестник Волгоградского государственного медицинского университета — 2007. — № 2. — C. 43-47.

23. Греясов В.И., Перфильев В. В., Сивоконь Н.И., Петриченко А. В. Технически сложные лапароскопические холецистэктомии // Эндоскопическая хирургия.— 1999.— № 1.—C. 18.

24. Gai H., Thiele H. Ultrasound selection criteria for laparoscopic cholecystectomy // Chirurg. — 1992.— Vol. 63. № 5. — P. 426-431.

25. Fitzgibbons R. J. Jr., Tseng A., Wang H. et al. Acute cholecystitis. Does the clinical diagnosis correlate with the pathological diagnosis? // Surg. Endosc. - 1996. Vol.10. № 12. - P. 1180-1184.

( ) Карсанов Алан Мухарбекович ( karsan@inbox.ru ), Маскин Сергей Сергеевич ( maskins@bk.ru ), Дербенцева Татьяна Викторовна (TVDerbentseva@volgmed.ru ), Ремизов Олег Валерьевич ( oleg_remizov@mail.ru ). Журнал «Современная наука: актуальные проблемы теории и практики» 